Journal of

International Logistics and Trade

\title{
Relationship between a Port's Reputation, Customer Satisfaction and Customer Loyalty
}

\author{
Hee-Sung Bae* \\ Department of International Trade, Tongmyong University, Busan, Korea
}

\begin{abstract}
ARTICLE INFO
Article history:

Received 08 March 2016

Accepted 20 September 2016

Keywords:

Busan new port

Reputation

Customer satisfaction

Customer loyalty

ABSTRACT

There are two objectives of this study: to analyze gaps in customer satisfaction and to test the customer loyalty gap on the basis of the reputation of Busan New Port. This study identifies the relationships between variables as well as the conceptual and operational definitions using prior research. Data was collected from 93 members of the International Freight Forwarders Association. The reliability and validity of the data was analyzed and the relationships between the variables were tested by analysis of covariance. The results are as follows: First, the reputation of Busan New Port means the abilities in which the port provides valuable benefits to international freight forwarders. The analytical results show that there is a gap in customer satisfaction between high- level and low- level reputation. Second, the levels of reputation are based on the gap in customer loyalty. This means that there are gaps in the friendly attitude of international freight forwarders and sustainable usage on the basis of the varying levels of port reputation.
\end{abstract}

\section{Introduction}

Reputation means the opinion of stakeholders and the behaviors and results of firms on the basis of the opinion. It supports decision-making of stakeholders through reasonable predication. Research on reputation of firms has been conducted from predominantly two viewpoints: first is the viewpoint of the similarity; that is, reputation is equal to the image of firms. Second is the viewpoint of the differences; that is, there are different viewpoints between reputation and image. In addition, there are two conflicting viewpoints: image is a larger concept than reputation, and vice versa. The concept of reputation can be applied to a port's reputation (Gotis and Wilson 2001). In this regard, a port's reputation is regarded as a cognitive expression on the degree of appreciation of port services (Fombrun and Shanley 1996; Kim and Joo 2008). Research on a port's reputation is not very widespread but there is the need for further study due to the importance in the South Korean economy.

Research has found that reputation has a positive effect on organizational loyalty (Kim and Kim 2014) as well as firms' value (Roberts and Dowling 2002). In addition, research results suggest that a port's reputation has a positive effect on customer loyalty (Kim and Joo 2008). These results may explain the positive relation between a port's reputation and customer loyalty. Reputation is regarded as an intangible resource and is estimated according to the associated value from stakeholders. Continuing port use can be the basis of customer loyalty and the port's reputational value is based on the causal link between reputation and customer loyalty. Therefore, the relationship between a port's reputation and customer loyalty can be explained through a resource-based view.

On the other hand, there are limitations of prior research. First, there are many research papers detailing a firm's reputation but there is a lack of research concerned with a port's reputation. Second, this research needs to test the gaps in customer satisfaction and customer loyalty between the high- level and the low- level reputation of Busan New Port.

\footnotetext{
${ }^{*}$ Corresponding author: Department of International Trade, Tongmyong University, 428, Sinseon-ro, Nam-gu, Busan, 48520, Korea Email: hsbae@tu.ac.kr
} 
Therefore, there are two objectives of this study: one is to examine the gap in customer satisfaction between the highlevel and the low- level reputation and the other is to analyze the gap in customer loyalty between these two levels of reputation.

\section{Prior research}

A port's reputation is regarded as an intangible resource, which is the value of ports that customers perceive (Roberts and Dowling 2002). The competitive advantage of ports derives from the managing, accumulating and locating this resource. In this regard, reputational differences of ports make heterogeneity hard to distinguish for competitors (Barney 1991). This results in sustainable strategic opportunity for realizing competitive advantage and the importance for ports to create value and place importance in intangible resources like reputation.

Prior research found that reputation is an important resource for generating sustainable competitive advantage (Barney 1991; Hall 1992; Roberts and Dowling 2002; Chang and Lee 2007). In spite of the importance of a port's reputation, there is little research concerning the relationship between reputation and customer loyalty. Kim and Joo (2008) identified that a port's reputation has a positive effect on customer trust and customer loyalty. Similarly, prior research confirmed that a firm's reputation has a positive effect on procuring intent and social connection (Kang et al. 2013), procuring intent (Kwag and Ryu 2014; Chon 2013) and organizational loyalty (Kim and Kim 2014). Kim et al. (2014) shows the relationship between new product development and the firm's value impacts a firm's reputation. In this regard, the relationship between a port's reputation and customer loyalty can be explained as a resource-based view (Kim et al. 2014). Ports have tangible and intangible resources; the former includes berth, the depth of water, and container terminals, and the latter contains port logistics services and reputation. In particular, a port's reputation encompasses the attractiveness as estimated by stakeholders. The reputation is formed by usage over a long period and includes utility, unique service aspects, non-substitutability and difficulty of imitation by competitors. The positive relation between reputation and customer loyalty is regarded as having causal ambiguity and social complexity because reputation is a determinant formed by stakeholders who use ports over a long period of time. Therefore, the relationship between a port's reputation and customer loyalty can be explained from a resource-based view.

Despite these theoretical relationships, prior research has limitations as follows: First, there is limited research concerning a port's reputation. Predominantly, research has examined the positive relationship between a firms' reputation and consumer purchasing intent. From the viewpoint of an intangible resource, a firms' reputation is based on a port's reputation (Kim and Joo 2008). As a result, there is little research on the relationship between a port's reputation and customer loyalty.

Second, additional analyses on reputation are required. Prior research verified the causal relationship between reputation and purchasing intent. However, it is possible to differentiate between high-level or low-level reputation for customers. This study analyzes the gap in customer loyalty between the high- level and the low-level reputation.

Third, there are many dependent variables determining a port's reputation excluded in previous research. Prior research considered two types of dependent variables concerning reputation: external factors, such as organizational loyalty and social connection, and internal factors, such as purchasing intent and customer loyalty. This study considers internal factors of stakeholders, such as customer satisfaction and customer loyalty, which influence a port's reputation. This can explain stakeholders' behavior toward a port's reputation. Two objectives of this study addressing these limitations include: to test gaps in customer satisfaction between the high level and low level of a port's reputation, as well as to analyze the gap in customer loyalty between these two levels.

\section{Research hypotheses and methodology}

\subsection{Port reputation and customer satisfaction}

Reputation plays an important role in establishing a firms' image as an intangible resource (Barnett et al. 2006), which increases a firms' performance when enhanced. In this respect, a port's reputation is an external value with characteristics of non-substitution and barriers of imitation from competitors (Barney 1991; Bae 2014). In addition, reputation has a direct effect on customer satisfaction as well as benefits for ports. Kim and Joo (2008) found that a port's reputation has a positive effect on customer satisfaction. Therefore, this study will test the following hypothesis:

\section{H.1: Higher port reputation relates to higher customer satisfaction.}

\subsection{Port reputation and customer loyalty}

Research has found the positive relation between customer satisfaction and customer loyalty (Fornell 1992). Customer satisfaction results from feelings about provided goods and services, and high- quality goods and superior 
services result in higher satisfaction. Customer satisfaction has a positive effect on repurchasing intentions (Lee 2000; Szymanski and Menard 2001; Lee and Kim 2008) as well as word of mouth intentions (Baek and Han 2007). Furthermore, customer satisfaction influences customer loyalty including repurchasing intentions and word of mouth intentions (Chaudhuri and Holbrook 2001). The relationship between customer satisfaction and customer loyalty can be explained as a behavior-cognition-response (Jin 2011). Service satisfaction by customers is concerned with cognition on behavior and this is connected with customer loyalty. Therefore, a high level of satisfaction relates to a high level of loyalty. This study will test the following hypothesis:

\section{H.2: Higher port reputation results in higher customer loyalty.}

\section{Research methodology}

\subsection{The definitions of the variables}

To achieve objectives of this study, the relationship between a port's reputation, customer satisfaction and customer loyalty is analyzed. The conceptual and operational definitions of the variables used in this study come from prior research. First, port reputation means the capability to provide customers with valuable port services (Dowling 2001; Kim and Joo 2008). It is measured as follows: there are various advantages when handling containers in Busan New Port, they have an important role when handling containers, they receive a high quality of customers' trust through handling containers, they contribute to the regional economy, and they provide customers with a high quality of services.

Second, customer satisfaction is defined as the gap between expected and perceived customer services (Anderson et al. 1994; Kim and Joo 2008). This is associated with inter-port competition between the Busan New Port and the Northern Busan Port. It is measured as follows: handling of containers has a positive effect on customer satisfaction in Busan New Port, the handling is deemed positive from the viewpoint of international logistics and the handling has a positive effect on port logistics services.

Third, customer loyalty is defined as sustained usage and a friendly attitude of customers toward Busan New Port (Chaudhuri and Holbrook 2001; Kim and Joo 2008). This is related to inter-port competition between the Busan New Port and the Northern Busan Port. It is measured using a Likert seven point scale from respondents as follows: customers prefer to have containers handled in Busan New Port, customers recognize the superior services of Busan New Port comparing the others and customers continuously use Busan New Port.

\subsection{Analytical methods}

This study considers international freight forwarders who are customers of Busan New Port. In particular, this study focuses on forwarders who provide shippers with multimodal transport services for container goods to verify gaps in customer satisfaction and customer loyalty between the high- level and the low- level reputation of Busan New Port. Questionnaires were sent to the membership list of Korean International Freight Forwarders Association which provides shippers with multimodal transport services. The questionnaires were collected by mail, e-mail, telephone, fax and personal visits. There were 93 questionnaires collected from September 2013 to November 2013.

This study analyzed data using various analytical methods. First, non-respondent bias was tested using the method recommended by Armstrong and Overton (1977). Collected questionnaires were divided into four groups and if there is no gap between responses of the first group and responses of the fourth group, there is no non-respondent bias. Study results show no gap between the two groups $(F=0.792, p=0.378)$.

Second, purification and estimation of data were tested as follows: First, there were omissions and missing values in the process of coding data. Omissions were inputted by confirmation of the questionnaires and row averages were substituted for missing data. Three preconditions of a multivariate analysis include normality, homoscedasticity and linearity. Normality was tested using a Kolmogorve-Smirnov test and results show no problem in normality $(p>0.1)$. Homoscedasticity was identified by scatter plot/dot plot and there was no problem identified due to all graphs showing upward trends. Linearity was tested using regression analysis and results reveal no problem $(F=393.882, p=0.000)$. There are no problems in multicollinearity results as the tolerance is $0.329(>0.1)$ and MAX-VIF is $4.191(<10.0)$. Second, item-total correlation and Cronbach's alpha (Nunnally 1978) were tested. A port's reputation showed that correlation coefficients were 0.781-0.893 $(>0.5)$ and Cronbach's alpha coefficient was 0.961 ( $>0.6)$. Customer satisfaction contained correlation coefficients of 0.888-0.902 (>0 0.5) and Cronbach's alpha coefficient of 0.963 (>0.6). Customer loyalty showed correlation coefficients of $0.891-0.929(>0.5)$ and Cronbach's alpha coefficient was 0.969 ( $>$ 0.6). There are no problems identified in these results. Third, factor analysis was performed. There are no problems if there is over 0.6 in factor loading coefficients, over 1.0 in eigenvalue and below $50 \%$ in percentage of variance. Additionally, results should exceed 0.5 for KMO (Kaiser-Meyer-Olkin) and the result of the Bartlett test should be supported. Correlation coefficients among the variables show the relationship between independent variables and 
dependent variables. If there are high correlation coefficients among dependent variables, gaps between independent variables should be tested by analysis of covariance.

Third, the relationships between the variables were tested by analysis of covariance if there are no problems in reliability and validity of the collected data. Analysis of covariance can identify gaps in dependent variables between clusters. This is especially valid for pure gaps in dependent variables between verified clusters due to a dependent variable is treated with covariate and the effect of it on the other dependent variable is excepted if there are high correlation coefficients between dependent variables. Analysis of covariance can test the pure gaps in a dependent variable between clusters negating the effect of the other dependent variable on a dependent variable. This provides better results than results of analysis of variance that contains type I error. The results are as follows.

\section{The results of empirical tests}

\subsection{The general characteristics of responding firms}

To achieve the study objectives, 93 data were collected and the general characteristics of respondent firms are as follows.

Table 1. The general characteristics of responding firms

\begin{tabular}{|c|c|c|c|}
\hline Types of business & Frequency $(\%)$ & Types of goods & Frequency (\%) \\
\hline Forwarders & $82(88.1 \%)$ & Petroleum goods & $5(5.4 \%)$ \\
\hline Others & $10(10.8 \%)$ & Industrial goods & $54(58.1 \%)$ \\
\hline Non-responding & $1(1.1 \%)$ & Others & $33(35.5 \%)$ \\
\hline Total & $93(100 \%)$ & Non-responding & $1(1.0 \%)$ \\
\hline The period of work & Frequency $(\%)$ & The number of staff & Frequency (\%) \\
\hline below 1 & $2(2.2 \%)$ & below 10 & $8(8.6 \%)$ \\
\hline $1-3$ & $15(16.1 \%)$ & $11-30$ & $38(39.8 \%)$ \\
\hline $3-5$ & $27(29.0 \%)$ & $31-50$ & $19(20.4 \%)$ \\
\hline $5-10$ & $13(14.0 \%)$ & $51-100$ & $7(7.5 \%)$ \\
\hline Over 10 & $35(37.6 \%)$ & Over 100 & $21(22.6 \%)$ \\
\hline Non-responding & $1(1.1 \%)$ & Non-responding & $1(1.1 \%)$ \\
\hline
\end{tabular}

General characteristics of responding firms are shown in Table 1. Type of business shows all responding firms are international freight forwarders because the sample frame is the membership list of Korean International Freight Forwarders Association. Others refer to forwarders who perform multimodal transport including port logistics services and bonded warehouses. Industrial goods are the most common type of good. Most respondents are regarded as experts, having worked more than 5 years as displayed in period of work. The number of staff shows that the most frequent number of staff surveyed is between 11 and 30 and this means that they are small and medium- sized enterprises. These results reveal high diversity among respondents. Next this study considers results of reliability and validity of data.

\subsection{The results of reliability and validity of data}

Before verifying relationships between the variables, reliability and validity of data were analyzed. These were tested using factor analysis and Cronbach's alpha.

Table 2. The results of reliability and validity tests

\begin{tabular}{lcll}
\hline Items & Factor loading & Reliability and validity & KMO \& Bartlett \\
\hline REP 2 & 0.731 & Cronbach's alpha: 0.940 & \\
REP 3 & 0.797 & Eigenvalue: 4.591 & KMO: 0.931 \\
REP 4 & 0.874 & \%V: 45.914 & Bartlett test \\
SAT 1 & 0.640 & Cronbach's alpha: 0.963 & Chi=1245.358 \\
SAT 2 & 0.644 & Eigenvalue: 2.681 & $d f=32$ \\
SAT 3 & 0.867 & $\%$ V: 44.688 & $p=0.000$ \\
LOY 1 & 0.630 & Cronbach's alpha: 0.947 & \\
LOY 2 & 0.764 & Eigenvalue: 2.981 & \\
LOY 3 & 0.872 & $\%$ V: 49.688 & \\
\hline
\end{tabular}

Notes) \%V: percentage of variance, Chi: Chi-square, REP: port reputation, SAT: customer satisfaction, LOY: customer loyalty 
The results of reliability and validity of data are shown in Table 2. First, factor loading coefficients exceed 0.6 for all data tested. However, REP 1 and REP 5 are included in two variables and as a result, they were removed. There were no problems with eigenvalue and Cronbach's alpha coefficients because the former exceeds 1.0 and the latter falls below 10.0 for all variables. Therefore, there were no problems in factor analysis results. Second, data stability was tested using a KMO and Bartlett test. There were no problems in the results due to the KMO exceeds 0.5 and an alternative hypothesis is supported by Bartlett test result. Next this study considers the results of correlation analysis.

Table 3. The results of correlation analysis

\begin{tabular}{|c|c|c|c|c|c|}
\hline Variables & Average & Standard deviation & Port reputation & $\begin{array}{c}\text { Customer } \\
\text { satisfaction }\end{array}$ & Customer loyalty \\
\hline Port reputation & 5.283 & 1.509 & 1.000 & & \\
\hline $\begin{array}{c}\text { Customer } \\
\text { satisfaction }\end{array}$ & 5.384 & 1.563 & $\begin{array}{c}0.939 * * * \\
(0.882)\end{array}$ & 1.000 & \\
\hline Customer loyalty & 5.351 & 1.565 & $\begin{array}{l}0.941 * * * \\
(0.885)\end{array}$ & $\begin{array}{l}0.953 * * * \\
(0.908)\end{array}$ & 1.000 \\
\hline
\end{tabular}

Correlation analysis tests the relationships between independent variables and dependent variables. If there is high correlation, this means that independent variables are explanatory variables of dependent variables. According to Table 3 , there is high correlation among independent and dependent variables. However, there is high correlation between customer satisfaction and customer loyalty which suggests ambiguity in the dependent variable gap results. In other words, it is not clear whether the gaps result from independent variables or from other dependent variables. In this case, analysis of covariance is used to verify the gap in a dependent variable between a high cluster and a low cluster of an independent variable after controlling the other dependent variable as covariate. The analysis of covariance results are as follows:

\subsection{The results of analysis of covariance}

The process of analysis of covariance is as follows: First, a port's reputation is classified into a high cluster and a low cluster to use cluster analysis. Second, an average and standard deviation of each cluster of customer satisfaction is calculated on the basis of the reputation. Third, the Levene's test is applied to determine error variance on customer satisfaction, and if a null hypothesis is supported, analysis of covariance is performed on the gap in customer satisfaction between the high- level and the low- level reputation. In addition, customer loyalty is tested using the same process of calculating average and standard deviation, as well as employing the Levene's test to determine error variance. The results are as follows.

Table 4. The result of cluster analysis on a port's reputation

\begin{tabular}{cccc}
\hline Variable & Cluster 1(69) & Cluster 2(24) & $F$ \\
\hline Port's reputation & 6.03 & 3.13 & $232.856^{* * *}$ \\
\hline
\end{tabular}

Table 4 displays the result of cluster analysis on a port's reputation. It is divided into two different clusters $(F=$ 232.856): cluster 1 has 69 firms (average=6.03) and cluster 2 has 24 firms (average=3.13).

Table 5. Descriptive statistics on customer satisfaction

\begin{tabular}{cccc}
\hline Cluster & Average & Standard deviation & $n$ \\
\hline 1 & 6.121 & 0.709 & 69 \\
2 & 3.264 & 1.400 & 24 \\
\hline Total & 5.384 & 1.563 & 93 \\
\hline
\end{tabular}

Table 5 displays descriptive statistics on customer satisfaction on the basis of the two clusters. Cluster 1 has 6.121 and cluster 2 has 3.264 as the average.

Table 6. Levene's test to equality of error variance on customer satisfaction

\begin{tabular}{ccccc}
\hline Dependent variable & $F$ & $d f 1$ & $d f 2$ & $p$ \\
\hline Customer satisfaction & 0.165 & 1 & 91 & 0.685 \\
\hline
\end{tabular}


Table 6 shows the result of Levene's test to determine error variance on customer satisfaction. The result shows that $p$ value is 0.685 and this means that it is possible to test analysis of covariance.

Table 7. The result of analysis of covariance on customer satisfaction

\begin{tabular}{cccccc}
\hline Contents & $\begin{array}{c}\text { Type III sum of } \\
\text { square }\end{array}$ & $d f$ & Mean square & $F$ & $p$ \\
\hline Corrected model & $204.659^{\text {a }}$ & 2 & 102.329 & 460.577 & 0.000 \\
Intercept & 1.437 & 1 & 1.437 & 6.466 & 0.013 \\
Customer loyalty & 59.326 & 1 & 59.326 & 267.024 & 0.000 \\
Reputation & 0.820 & 1 & 0.820 & 0.058 \\
Error & 19.996 & 90 & & 0.222 & \\
\hline Total & 2920.000 & 93 & & \\
\hline Corrected total & 224.655 & 92 & & \\
\hline${ }^{2}=0.991\left(\right.$ adj $\left.R^{2}=0.909\right)$, dependent variable: customer satisfaction & &
\end{tabular}

Table 7 shows the result of analysis of covariance on customer satisfaction between the two clusters after controlling for customer loyalty. The hypothesis is not supported (criterion: $p<0.05$ ), meaning that the gap in customer satisfaction between the two clusters is affected by customer loyalty.

Table 8. Descriptive statistics on customer loyalty

\begin{tabular}{cccc}
\hline Cluster & Average & Standard deviation & $n$ \\
\hline 1 & 6.092 & 0.758 & 69 \\
2 & 3.222 & 1.310 & 24 \\
\hline Total & 5.351 & 1.565 & 93 \\
\hline
\end{tabular}

Table 8 shows the average and standard deviation of customer loyalty in the two clusters. The average of cluster 1 was found to be 6.096 and the average of cluster 2 was 3.222 .

Table 9. Levene's test to equality of error variance on customer loyalty

\begin{tabular}{lllll}
\hline Dependent variable & $F$ & $d f 1$ & $d f 2$ & $p$ \\
\hline Customer loyalty & 2.732 & 1 & 91 & 0.102 \\
\hline
\end{tabular}

Table 9 shows the Levene's test results for error variance on customer loyalty. There is no problem in the result because $p$ value is 0.102 .

Table 10. The result of analysis of covariance on customer loyalty

\begin{tabular}{|c|c|c|c|c|c|}
\hline Contents & $\begin{array}{c}\text { Type III sum of } \\
\text { square }\end{array}$ & $d f$ & Mean square & $F$ & $p$ \\
\hline Corrected model & $205.387^{\mathrm{a}}$ & 2 & 102.693 & 466.660 & 0.000 \\
\hline Intercept & 1.311 & 1 & 1.311 & 5.958 & 0.017 \\
\hline Customer loyalty & 58.761 & 1 & 58.761 & 267.024 & 0.000 \\
\hline Loyalty & 1.060 & 1 & 1.060 & 4.818 & 0.031 \\
\hline Error & 19.805 & 90 & 0.220 & & \\
\hline Total & 2888.333 & 93 & & & \\
\hline Corrected total & 225.192 & 92 & & & \\
\hline
\end{tabular}

Table 10 displays the analysis of covariance results on the gap in customer loyalty between the high cluster and the low cluster of a port's reputation. The result shows that $p$ value is 0.031 and the hypothesis is supported. The result means that there is a pure gap in customer loyalty between the clusters of the reputation excluding the effect of customer satisfaction. This is a different result from customer satisfaction and in-depth discussion follows.

\subsection{Discussion}

The analytical results are as follows: First, a port's reputation refers to capability of a port to provide international freight forwarders with valuable services. The sample firms are divided into two clusters: firms with a high-level 
reputation and firms with low-level reputation. The result shows that the gap in customer satisfaction between the two clusters is affected by customer loyalty. This reflects there are no gaps between customers' expectations of services and perceived performance on the basis of capabilities where ports provide international freight forwarders with valuable services. In other words, the gap in customer satisfaction between the clusters is affected by customer loyalty.

Second, results show a pure gap in perceived customer loyalty between two clusters of a port's reputation, excluding the effect of customer satisfaction. This means that there is a gap in the friendly attitude and on-going use of international freight forwarders at Busan New Port on the basis of capabilities where the port provides international freight forwarders with valuable services. These results are consistent with similar findings from Kim and Joo (2008). This means that reputation consists of characteristics of internal resources of ports because it is useful, rare, non-substitutable and difficult to imitate. In addition, reputation has the characteristics of causal ambiguity and social complexity on the relationship with customer loyalty (Barney 1991).

\section{Conclusion}

The objectives of this study were to verify gaps in customer satisfaction between the clusters of a port's reputation and to test gaps in customer loyalty between these clusters. To achieve the objectives, 93 international freight forwarders were surveyed. Reliability and validity of data were tested and hypotheses were tested by analysis of covariance. The theoretical implications of the results were explained in the discussion section, and managerial implications, limitations and recommended future research focus follows.

Managerial implications of the results are as follows: Managers of Busan New Port should recognize a gap in customer loyalty between the levels of reputation of a port. In this regard, managers of Busan New Port should focus on developing services to handle containers in Busan New Port. This highlights the importance of handling containers and results in intensive investment by Busan New Port. In addition, international freight forwarders highly regard the handling of containers and positive effects flow to the local economy. As a result, managers should emphasize the importance of container services and promote sustainable investment.

The cluster which has a high reputation of Busan New Port shows a high level of customer loyalty. This means that international freight forwarders which place higher value on the services of Busan New Port have higher preference for using the port, places higher value on its services, and higher frequency of use. Therefore, managers of the port need to provide superior service for international freight forwarders and as a result, a high reputation is the cause of high customer loyalty.

This study has the following limitations: First, the relationship between reputation and customer satisfaction is affected by customer loyalty. This means that the relationship between reputation and customer satisfaction is unclear. Additional research on this relationship is required. Second, the sample size used in this study is small. Broadening the scope to include more of the customers would yield better results. These limitations should help guide future research.

\section{References}

Anderson, E.W., Fornell, C., Lehmann, D.R., 1994. Customer satisfaction, market share and profitability: findings from Sweden. Journal of Marketing 58, 53-66.

Armstrong, J.S., Overton, T.S., 1977. Estimating nonresponse bias in mail surveys. Journal of Marketing Research 14, $396-402$.

Bae, H.S., 2014. The interactive effect of supply chain integration on performance of international freight forwarders. Journal of International Logistics and Trade 12, 97-119.

Baek, M.Y., Han, S.L., 2007. Retailer's service quality on customer value, customer satisfaction and word-of-mouth intention. Journal of Korean Service Management Society 8, 79-103.

Barney, J., 1991. Firm resources and sustained competitive advantage. Journal of Management 17, 99-120.

Barnett, M.L., Jermier, J.M., Lafferty, B.A., 2006. Corporate reputation: the definitional landscape. Corporate Reputation Review 9 , 26-38.

Chang, Y.T., Lee, P.T.W., 2007. Overview of interport competition: issues and methods. Journal of International Logistics and Trade $5,99-121$

Chaudhuri, A., Holbrook, M., 2001. The chain of effects from brand trust and brand affect to brand performance: the role of brand loyalty. Journal of Marketing 65, 81-93.

Chon, M.B., 2013. A study of the location of foreign firms and CSR activity: focusing on the mediating effect of reliability, commitment, and corporate reputation. Korean Journal of Corporate Business 20, 103-123.

Dowling, G.R., 2001. Creating Corporate Reputation - Identity Image, and Performance. Oxford University Press, Oxford, UK.

Fombrun, C., Shanley, M., 1996. Reputation: Realizing Value from the Corporate Image. Harvard Business School Press, Boston, MA.

Fornell, C., 1992. A national customer satisfaction barometer: the Swedish experience. Journal of Marketing 56, 6-21.

Gotis, M., Wilson, A.M., 2001. Corporate reputation: seeking a definition. Corporate Communications: An International Journal 6, 24-30.

Hall, R., 1992. The strategic analysis of intangible resources. Strategic Management Journal 13, 135-144. 
Jin, C.H., 2011. The relationship between consumers awareness, image, perceived quality toward private brand and brand loyalty. Korean Journal of Business Administration 24, 3461-3480.

Kang, J.H., Song, J.M., Jeon, I.K., 2013. The structural relationship among CSR on corporate performance use sports and consumers' attitude, corporate reputation, perceived social connectedness, purchase intention consumer. The Korean Journal of Sports Science 22, 545-563.

Kim, B.A., Lee, J.K., Song, S.Y., 2014. Radical and incremental new products and firm value in pharmaceutical industry: moderating role of firm reputation. Korean Business Review 43, 443-463.

Kim, M.K., Kim, Y.S., 2014. A study on the effect of food service enterprise's social responsibility participation on employees' firm reputation and organization loyalty. Internal Journal of Tourism and Hospitality Research 28, 197-211.

Kim, S.Y., Joo, H.Y., 2008. The structural relationship among port logistics service quality, port reputation and customer loyalty of liner ships. Korean Trade Review 33, 1-30.

Kwag, D.H., Ryu, K.S., 2014. The relationships between corporate social responsibility (CSR), corporate reputation, and behavior intention: the case of S brand. Journal of Foodservice Management Society of Korea 17, 33-52.

Lee Y.J., 2000. Generalized research on customer satisfaction. Korean Society of Consumer Studies 11, 139-166.

Lee, Y.O., Kim, M.S., 2008. The effect of logistics service quality on customer satisfaction and repurchase intention: focusing on company size as a moderator. Journal of International Logistics and Trade 6, 55-73.

Nunnally, J., 1978. Psychometric Theory. McGrow-Hill, New York.

Roberts, P.W., Dowling, G.R., 1997. The value of a firm's corporate reputation: how reputation helps attain and sustain superior profitability. Corporate Reputation Review 23, 1077-1093.

Szymanski, D.M., Menard, D.H., 2001. Customer satisfaction: a meta-analysis of the empirical evidence. Journal of Academy of Marketing Science 29, 16-35. 